\title{
Sustainable Tourism Destination Assessment as a Baseline for Tanjung Kelayang Tourism Development
}

\author{
Herdi Andrariladchi ${ }^{1}$, Narumon Arunotai ${ }^{2}$ \\ ${ }^{1}$ Department of Environment Development and Sustainability, Faculty of International Graduate School, Chulalongkorn University, Bangkok, Thailand \\ 2 Social Science Research Institute, Chulalongkorn University, Bangkok, Thailand
}

\begin{abstract}
Tourism is a complex and prominent sector in Indonesia that involved many stakeholders. Led by the success story of Bali tourism development which able to grow beyond all expectation, helping to improve public and private infrastructure, including the birth and growth of small-medium enterprises, led the Indonesian government to distribute and spread the development all over Indonesia through Ten New Bali concept. One of these is Tanjung Kelayang, located in Belitung Island. Despite Bali success stories, negative impacts of Bali tourism development on environmental sustainability appeared, such as land-use change, soil and water degradation, pollutions, waste mismanagement, etc. Reflected from Bali negative tourism impact, this paper will identify and analyse Tanjung Kelayang tourism development as a New Bali using sustainable tourism destination criteria to create baseline data. A qualitative approach using both primary data by on-site observation and in-depth interview with related parties, and secondary data by identifying the Local Official Tourism Development Master Plan (RIPPARKAB) year 2014 and other studies in regards with Tanjung Kelayang tourism development by using GSTC-D V2 as a tool to reflect sustainability commitment was occurred on this paper. The result of compliance shows that only 19\% for Sustainable Management, 4\% for Socio-Economy Sustainability, 11\% for Cultural Sustainability, and $0 \%$ for Environmental Sustainability. Thus, it shows the gap of Tanjung Kelayang tourism development in regards with sustainable destination concept. Hence, a commitment, communication, and cooperation from all related parties is necessary to be in place to achieve a sustainable tourism destination development in Tanjung Kelayang.
\end{abstract}

\section{CONTACT}

herdyladchi@gmail.com

\section{KEYWORDS}

Sustainable Tourism Destination, Tanjung Kelayang, Global Sustainable Tourism Council (GSTC)

\section{INTRODUCTION}

Tourism is the third focus sector in Indonesia which helps the economic and livelihood development both for the urban and non-urban areas. As a complex sector that involved both direct and indirect enterprise led tourism sector to create more benefits and advantages to all layers and business levels (small, medium, and big scale), and also help the local, regional, and national economic development ${ }^{[31,36]}$. In such a way, Bali becomes the perfect example of how the tourism sector could be successful and promising to the development. As a positive impact, Bali shows a considerable improvement both for private and public infrastructure, giving birth and growing a small-medium and local enterprise, develop the local economy, increased the industry demand, and increased employment opportunity, and help to reduce labour force [3]. Hence, these positive and prominent impacts from tourism encourage other regions to follow their steps. In 2015, the Indonesian government, the Mr President, and the Ministry of Tourism established the New Bali. This concept was created by choosing ten (10) destinations, including Lake Toba, Tanjung Kelayang, Tanjung Lesung, Kepulauan Seribu, Borobudur Temple, Mount Bromo, Mandalika, Labuan Bajo, Wakatobi, and Motrotai Island, with the top-down approach of attraction, accessibility, and amenities, which aims to distribute the tourism development to all over Indonesia [11, 14, 21].

Moreover, tourism becomes a post-mining economic and strategic transition development in Belitung. Supported by the landscape, natural condition, and resources, social community, and located not far away from the capital city of Indonesia Jakarta, become a good potential for future development. Tanjung Kelayang destination has potential towards marine tourism supported by white sand, granite stone, and the blue ocean. Thus, this paper will focus on Tanjung Kelayang destination, Belitung Island.

However, with all positive and promising tourism development stories, slowly but sure, Bali tourism development shows a backward impact of tourism development. Many problems appear along with the development such as; land-use change, lack of freshwater for the local residence, and increased pollution in the air and water [40-41]. These issues appeared and grew significantly due to the sustainability concept's disobedience on Bali tourism development ${ }^{[46]}$. Accordingly, Tanjung Kelayang must learn from the unsustainable tourism development in Bali and make a better development with a good strategy and planning comply with principle, criteria, and indicator of sustainable tourism destination. 
As the first organization that supported by international recognition, Global Sustainable Tourism Council (GSTC) has created sustainable tourism standards for the tourism industry and destination to guide the tourism development all over the world to be more sustainable and balance their development to the social, cultural, community, and environment [18]. Hence, the objective of this paper will be as following;

1. Assess the level of compliance of master plan strategy from Tanjung Kelayang tourism development with the GSTC Destination assessment.

2. Identify and analyse the gap from the report of RIPPARKAB document 2014 with the GSTC Destination Indicators Version 2 or GSTC-D V2.

\section{METHODS}

This paper will be obtained by qualitative approach with primary and secondary data. Primary data should be collected from the first-hand experience which yet published with the authentic and objective ${ }^{[22]}$. While, secondary data should be based on the document and text [33], collected from the previous study, journal, books, and any material data from the official statistic, government administrative, etc., which is relevant to the research [20]. Accordingly, secondary data could be collected from the publication, website, books, articles, records, government documents, etc., [1]. Thus, this paper will use primary data through field observation which conducted from April to May 2021 in Tanjung Kelayang, another primary data also collected through the in-depth interview with related stakeholder, ten participants were interviewed using face-to-face interview, five participant are from Belitung government as a key stakeholder which concern regarding tourism development, while the other five participant are from the local enterprise and local community surround Tanjung Kelayang. While for the secondary data, the data will be collected through the government document report of Local Official Tourism Development Master Plan (RIPPARKAB) report 2014, previous study regarding tourism development in Tanjung Kelayang, and GSTC website. Moreover, the paper will be analyzed using GSTC-D V2 to measure compliance with the sustainability indicator on Tanjung Kelayang tourism development.

\section{RESULTS AND DISCUSSIONS}

The GSTC-D V2 consists of 4 sections; 10 principles, 33 criteria, and 107 indicators, where this requirement will describe the level of compliance against sustainable tourism development standards. The component of the standard as the following information below:

Table 1. GSTC Principles Table

\begin{tabular}{l|l}
\multicolumn{2}{c}{ Table 1. GSTC Principles Table } \\
\hline Section A: Sustainable Management & Section C: Cultural Sustainability \\
A(a) Management Structure and Framework & C(a) Protecting Cultural Heritage \\
A(b) Stakeholder Engagement & C(b) Visiting Cultural sites \\
A(c) Managing Pressure and Change & \\
& \\
\hline Section B: Socio-Economic Sustainability & Section D: Environmental Sustainability \\
B(a) Delivering Local Economic Benefits & D(a) Conservation of Natural Heritage \\
B(b) Social Wellbeing and Impacts & D(b) Resource Management \\
& D(c) Management of Waste and Emissions \\
\hline
\end{tabular}

\begin{tabular}{|c|c|c|c|}
\hline Compliance (C) & $\begin{array}{l}\text { Compliance with } \\
\text { Observation (CO) }\end{array}$ & Non-Compliance (NC) & Non-Applicable (NA) \\
\hline $\begin{array}{l}\text { The destination has } \\
\text { been complied with } \\
\text { and implemented } \\
\text { without any problems }\end{array}$ & $\begin{array}{l}\text { The destination has } \\
\text { been established and } \\
\text { implement some of the } \\
\text { indicators and still } \\
\text { facing some troubles in } \\
\text { the way of indicators }\end{array}$ & $\begin{array}{l}\text { The destination yet } \\
\text { implement and } \\
\text { established the } \\
\text { indicator }\end{array}$ & $\begin{array}{l}\text { The indicator does not } \\
\text { apply to the destination }\end{array}$ \\
\hline
\end{tabular}

According to the analysis, the result showed:

1. Section A. Sustainability Management

1.1 Principle A(a) Management Structure and Framework; level of compliance on this section was 34\%, consist of 4 indicators comply and 7 indictors not-comply with the requirement and 1 compliance with observation, as described in the chart and table below: 
Figure 1 Principle (A)a
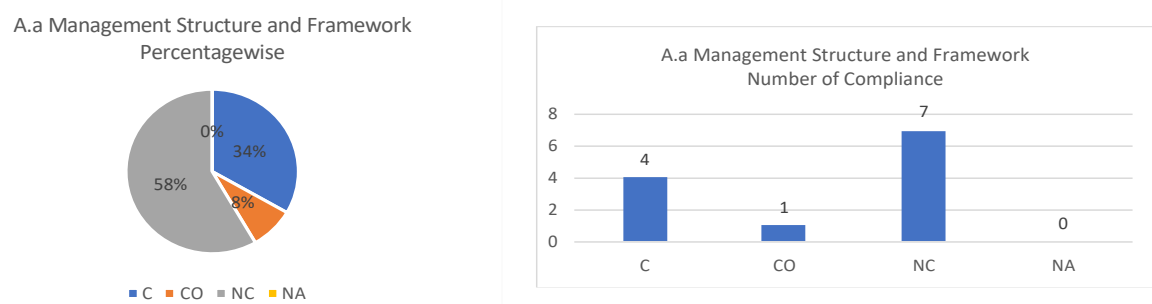

The main issue of non-compliance in this requirement was the inability of the organization to define the responsibility. Capability to manage the socio-eco-cultural and environmental issues; commitment to transparency; knowledge to identify the tourism assets; and absence of periodically monitoring, evaluation and review to ensure the organization and destination already operate on the right track, and the result shall be publicly available. Against these problems, the level of knowledge and understanding in sustainable management is low. The organization also shows that they could not identify the management structure and framework as the baseline for the coordinating process. Furthermore, it also found that stakeholder engagement is not taking place to develop the strategy. The organization only designs the organisation's development program without any involvement, communication, or consultation with the related parties. As a result, the absence of periodic monitoring, evaluation, and review process appears to be other issues on the development. While for the compliance part, the destination has established the organization in place, such as the tourism activist group (POKDARWIS), as a local community organization concerned about tourism development in Belitung. The Belitung government has also established the RIPPARKAB, which shows the strategy and action plan publicly available.

Following the criteria, the destination is required to establish an effective organization with the responsibilities, oversight, and implementation capability for sustainable management with the transparency operation and transaction ${ }^{[10]}$. It is required to measure the level of understanding of sustainability and the commitment from the organization to the sustainable tourism criteria. The destination also has to establish the strategy and the action plan with the sustainability concept of socio-economy, cultural and environmental with the stakeholder's involvement, especially local community involvement [10], to measure stakeholder engagement level from the critical factors on planning the strategy. Moreover, the monitoring and reporting system is necessary to identify the difficulties the destination might face, which is regularly monitored and annually reported ${ }^{[10]}$ to ensure the implementation and difficulties.

1.2 Principle A(b) Stakeholder Engagement; showed the non-compliance dominated the percentages with $80 \%$ in total of 8 indicators and $20 \%$ of compliance with observation and $0 \%$ for the compliance and the non-applicable, as described in the chart and the table below;

Figure 2 Principle A(b)
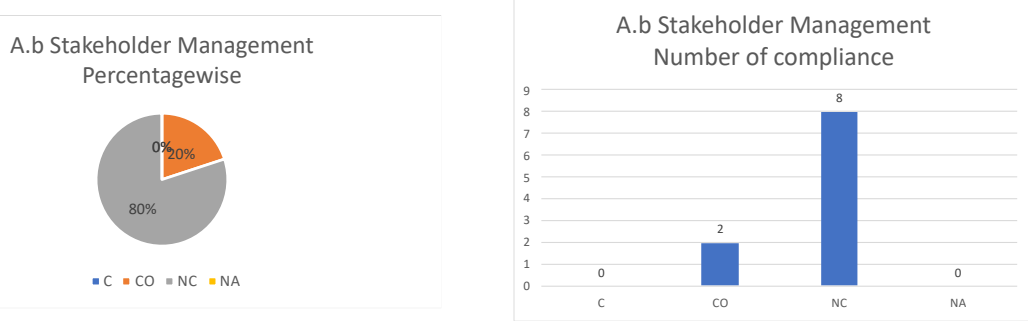

The non-compliance within the principle appeared due to the absence of the data regarding the understanding, satisfaction, aspiration, engagement, communication, and assessment on sustainability from tourism business, local community, and visitor. Another non-compliance also concerns the lack of attention and awareness concerning certification schemes in the tourism industry. According to the RIPPARKAB document 2014, the document only provides information towards tourism destination location, number of hotels, number of travel agencies, number of visitors from the previous year, and the visitor target in the next year and long-term future. Meanwhile, stakeholder's engagement documentation, including reporting, monitoring, and evaluation results, described the level of commitment and stakeholder's involvement, which was not in place. A small, good activity obtained from RIPPARKAB document 2014 was promoting the destination through the cultural event initiated by the Local Official Tourism of Belitung. 
Following the criteria, the destination should be in periodically to communicate, inform, educate, and encourage all related parties, including the tourism industry, local community, and visitor, on the sustainability issues and the standards required to the stakeholders to be followed [10], due to the concept of the successful tourism industry is to recognize and deal with wide range factors that required effective communication and the combination of control and adaptation to minimize future risk [13]. Thus, the reporting and certification procedure and system have been promoted by tourism enterprises as self-regulations will help them comply with regulations and improve their commitment to environmental management and social sustainability [7]. Moreover, local community empowerment on tourism development must be implemented through the mature plan, effective strategy, periodic monitoring and evaluation, and participation [38]. Thus, local community participation means accepting the local perspective concerning the programs and activity without any pressure [4]. It is to prevent future risk, improving the local livelihood, and protecting the relationship with residence ${ }^{[16]}$. As a public sectoral, the government has a crucial role in the development and management system ${ }^{[34]}$. Accordingly, provide the training, course, and education to improve the knowledge and skills on sustainability to optimize resources, public organization, local trust, and satisfaction concerning tourism development [38]. Hence, regulations policy, guidelines, master plan, and strategy with public participatory and involvement are necessary to ensure the voice from the local and make the same vision and mission between the stakeholders ${ }^{[10]}$, to prevent future risk.

Furthermore, the role of sustainable tourism, according to UNWTO, is to be a policy and strategy development with a broader perspective and careful planning with a resources management consideration and stakeholders engagement coordination [43]. In such a way, as a policymaker, the government becomes a centre point on developing sustainable development implementation and destination management [29]. Moreover, visitor management is necessary to be in place due to they become the key roles directly experience sustainability in the destination [34]. Likewise, the concept of guilt should be in place to increase tourist awareness towards environmental issues in a long-term vision of changing responsible tourists' perspectives [5]. Hence, a mandatory policy concerning the certification scheme will help the destination ensure compliance.

1.3 Principle A(c) Managing Pressure and Change; on this section, percentages of compliance is $25 \%$, while the number of non-compliance dominant the percentages with $67 \%$ and the compliance with observation becomes less with only $8 \%$, as described as in the chart and the table below;

Figure 3 Principle A(c)
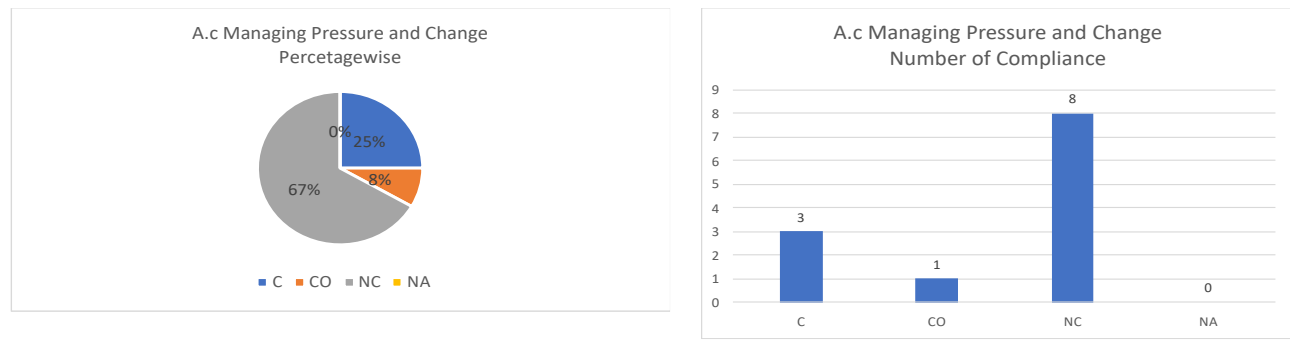

The main issues on non-compliance in this requirement were the unprepared system regarding visitor management and the following action to measure the tourist volume. The absence of the data, strategy, planning, mechanism, and procedural towards climate change and adaptation and crisis management risk also appear in Tanjung Kelayang tourism development. According to the RIPPARKAB document 2014, no mechanism in place mentioned how to control and monitor the visitor number and activities in the destination. The data only mention the target of visitor numbers to increase local GDP without any concern of future risk, i.e., mass tourism, uncontrolled tourism development, and crisis that might affect the environment and the development. The absence of the data co climate adaptation also appeared as the non-conformity on this criteria. However, the RIPPARKAB document 2014 shows vital regulations planning (local regulations No. 12/2015) concerning the Master Plan of Tourism Development in Belitung, and the tourism destination development in Belitung is required to follow the eco-enviro-socio-friendly.

Following the criteria, the destination must measure visitor flow with the volumes and the activities to identify the impacts and the destination target ${ }^{[10]}$. It is also to identify the number of people at the destination and avoid mass tourism that might appear due to over-tourism, leading to a destructive environment [36]. Accordingly, the identification of visitor management flow is necessary to measure the traffic congestion and pollutions on the destination to meet tourist and local needs and wants [26]. Risk management in the tourism context refers to the planning and implementing processes directed towards managing the negative affect and alternative solutions ${ }^{[4]}$. 
The destination is also required to identify the risk, crisis management, and opportunities on climate change adaptation and the strategy, management, design development, and information regarding climate change that publicly available ${ }^{[10]}$. Profound analysis of climate change impacts and climate change vulnerability become the essential information to plan the strategy to prevent future risk ${ }^{[3]}$. Lack of specific data, knowledge, report and policy document, and analysis of climate change risk and adaptation in tourism development become the vast gap that should be solved [25]. The case study of a small island in the Bahamas shows the issues on climate change risk adaptation were appeared due to the lack of management and preparation towards climate change issues; as a result, the analysis shows a considerable problem might arise in the future, which could destroy the island, accommodation, and the local residence; hence, an integrated coastal zones management and tourism development strategy in regards to the adaptation measurement on climate change is necessary to obtain [32].

\section{Section B. Socio-Economic Sustainability}

2.1 Principle B(a) Delivering Local Economic Benefits; on this section, the non-compliance almost dominates the percentages with $83 \%$ and $17 \%$ for the compliance with observation and $0 \%$ for the compliance and nonapplicable, as described as in the chart and table below;

Figure 4 Principle B(a)

PRINCIPLE Ba Delivering Local Economic Benefits Percentages

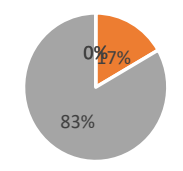

- $\mathrm{C}\|\mathrm{CO}=\mathrm{NC}\| \mathrm{NA}$

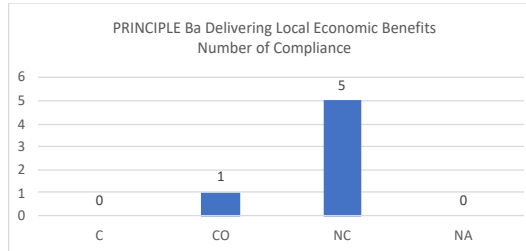

This principle's non-compliance appears due to the absence of the data regarding indirect economy contribution, decent work, career opportunity, and equality on local community employment. At the same time, the lack of data on the fair trade on local products becomes the compliance with the observation that needs to be solved. According to the interviews with the local residence, a lack of encouragement and monitoring from the destination concerning training, safety, and secure advancement create a gap in the local community's development.

As required by the criteria, annual reports on the economic impact and contribution direct and indirect contribution are necessary [10]. In line with the statement from WTC, which believes that in travel and tourism, a sustainability reporting system is required and becomes a critical factor in engaging the stakeholders, identify the problems, and measure the organization and operation [47] These actions will also help raise the enterprise's credibility ${ }^{[4]}$.

Moreover, the destination should preserve the local community's training, including women, young people, minorities, and people with disabilities, to increase their knowledge and skills to help the local community get legal employment [10]. Accordingly, the local community's role in economic development becomes a resource to influence local potentials [39]. Moreover, the government's commitment to the local community and small-medium enterprise must be in place and the fair trade in the destination [10]. Furthermore, the inequalities rate on tourism development creates a huge gap between the big-scale business and small-scale business; therefore, a fair trade concept becomes a solution to promote balanced development and alleviation of poverty ${ }^{[8]}$. Hence, fair trade will help to improve the local economic livelihood.

2.2 Principle $\mathbf{B}(\mathbf{b})$ Social Wellbeing Impacts; on this section, non-compliance almost dominate the percentages with $92 \%$ and the compliance only $8 \%$ and $0 \%$ for the compliance with observation and nonapplicable, as described in the chart and table below; 
Figure 5 Principle $\mathrm{B}(\mathrm{b})$
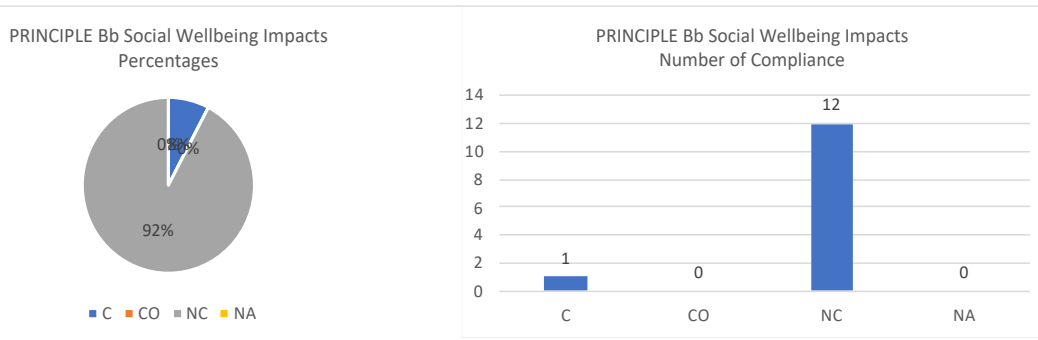

The main issues of non-compliance in this section were the absence of a system to measure the stakeholder's sustainability engagement; the code of conduct, reporting on exploitation and discrimination, which also publicly communicated and enforced; the crime, safety, health, and hazard system data in the destination; liability insurance; public consultation system to protect the user and access right to the resources; and information destination data to support people with disabilities. However, RIPPARKAB has been written Article 5 UU Number 10, 2009, as a basic regulation on the human rights commitment for tourism development.

Following the criteria, the destination is required to establish a system that could help engage the tourist, enterprise, and public to contribute against community development and sustainability in a responsible manner [10], due to the complex concept of sustainability, which needs cooperation from all related parties, including private, individuals, and government, which becomes a regulator on the development [7]. Moreover, the destination should establish guidelines to prevent the exploitation and discrimination on human trafficking, modern slavery and commercial, sexual, and any other exploitation and discrimination against minority, women, LGBT, race, religion, etc., by conducting periodic monitoring and reporting on the destination [10]. Following the fact regarding human rights in tourism development, some issues appeared, including; lack of employment, unbalance development, loss of access to resources, lack of green areas, loss of water for the local community, increase discrimination against the local residence, and many more [6]. Hence, a policy, regulations, comment, suggestion, and complaint box should be transparent and publicly available to ensure and measure compliance and understanding of exploitation and discrimination. Accordingly, the sustainable development of tourism will never be achieved until human rights are legitimate by all related parties [15]. In such a way, communication with all related parties towards human rights issues is necessary with a declaration and commitment from public sectors on laws of prosecution of child abuse crime, integration of human right with the legal instrument, national minimum wages, obligatory human rights impact assessment with the instrument, campaign, and monitoring need to be in place ${ }^{[6]}$.

Furthermore, liability such as a legal document is necessary to prevent future risk [10]. One example of the violation of human rights occurred in Alleppey, Kerala, India, where tourism activity harms the local community with the sewage pumped, leading to water pollutions, and kicked out the local community with a small compensation without particular livelihood [15]. On this basis, providing land ownership and community property is necessary ${ }^{[6]}$. Hence, to prevent those kinds of action, liability insurance and the legal document must be obliged. While, Health, safety, hygiene, and security also need to be in place in all facilities, destinations, hotels, etc., to ensure the safety of tourists ${ }^{[10]}$.

\section{Section C. Cultural Sustainability}

3.1 Principle C(a) Protecting Cultural Heritage; on this section, the compliance percentages is $22 \%, 11 \%$ of non-applicable, $67 \%$ of non-compliance, and $0 \%$ for compliance with observation, as described in the chart and table below;

Figure 6 Principle C(a)

PRINCIPLE Ca Protecting Cultural Heritage Percentages

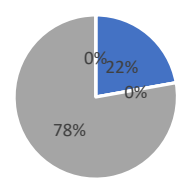

- $\mathrm{C}=\mathrm{CO}=\mathrm{NC}=\mathrm{NA}$

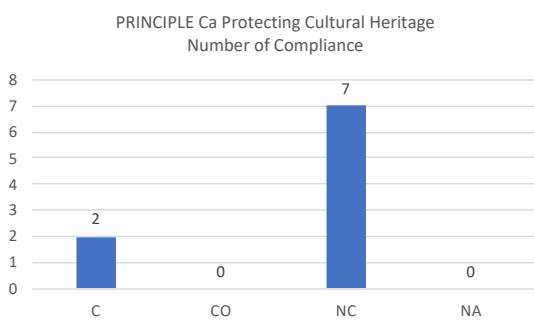


The point of compliance in this section covered the event towards the culture and heritage involved in the local community to provide a genuine experience for the tourists. However, the non-compliance on these sections appears due to the unavailable data concerning evaluation, monitoring system, laws, historical sales, conservation and rehabilitation, and the protection and preservation of the intellectual property of the community and individuals. According to the interviews with the local community, lack of communication and interaction from the destination to the local community's pertaining to the regulations create a gap of knowledge for the residents.

Following the criteria, the destination must have a list of cultural assets that describe the indication of vulnerability and the program to conserve and mechanism to support the conservation and the list of intangible cultural heritage and the celebration with the local community involvement ${ }^{[10]}$. Due to the role of cultural heritage, which become a sum on culture and beliefs that covered the environment, social, individuals, and ecosystem surround [24]. On this basis, laws and regulations are necessary to be in place to ensure and secure the heritage [28]. Moreover, cultural artefacts also need to be secure to protect the legal trade [10]. Hence, a proper intellectual property and monitoring system towards the cultural heritage in the destination is necessary to protect the cultural heritage ${ }^{[10]}$.

3.2 Principle C(b) Visiting Cultural Sites; on this section, the non-compliance dominate the percentages with $100 \%$, as described in the chart and table below;

Figure 7 Principle C(b)
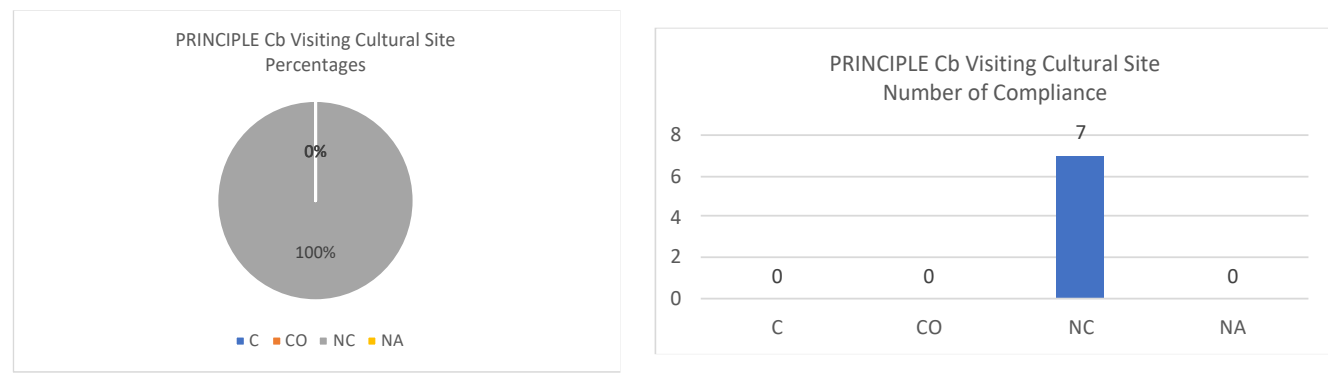

The non-compliance of this section is due to the non-appearance data regarding visitor management and destination management within and around the cultural sites; the absence of the data concerning the capacity, sensitivity, site interpretation, and the guidelines for visitor behaviour at the sensitive areas and cultural event; the lack of significant message for tourist in the destination in regards the cultural appropriation that exists surround the destination which communicated in several languages (easy to understand);

Following the destination criteria, public consultation should be obtained to get comprehensive knowledge and understanding of the local norms and regulations pertaining to the cultural site. A visitor flow impact assessment is also required to track and identified the development along with the monitoring, reporting, and evaluating system ${ }^{[10]}$, especially in the non-urban areas which preserve a natural, ecological, and sensitive nature ${ }^{[45]}$. Thus, visitor management became a tool to measure the carrying capacity and the environmental conservation to ensure the environment, socio-cultural protection, and tourist satisfaction on the destination [23]. Furthermore, a provision of guidelines is necessary to be in place to remind the tourist in regards to the destination laws ${ }^{[10]}$.

\section{Section D Environmental Sustainability}

4.1 Principle D(a) Conservation of Natural Heritage; In this section, the level of non-compliance $100 \%$ dominate the percentages, and it is $0 \%$ for compliance, compliance with observation, and non-applicable indicator, as described in the chart and table below;

Figure 8 Principle D(a)

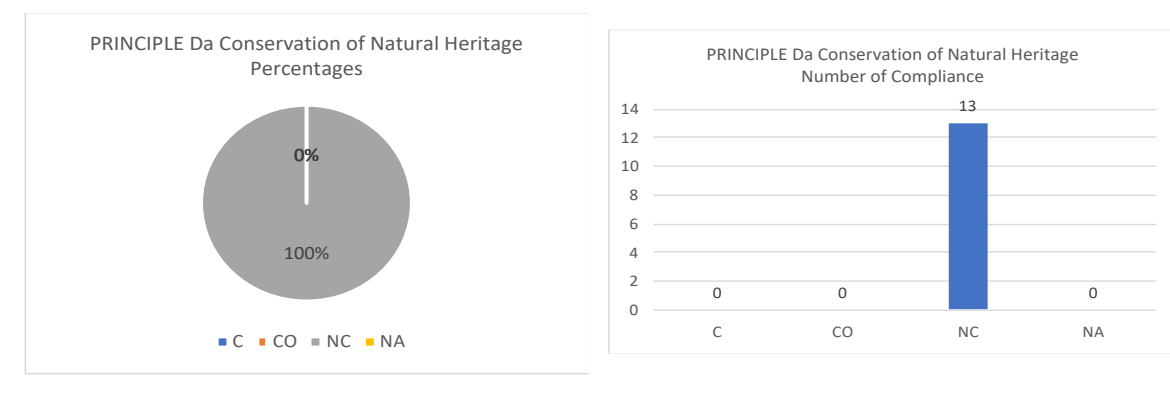


The non-conformity problems have covered the absence of the system to measure the environment, visitor, natural site, wildlife interaction, and animal welfare which also covered; conservation, ecosystem, habitats, species; destination characteristic, capacity, and sensitivity; destination behaviour guideline; wildlife interaction; living organism welfare; and living organism endanger species data and protection.

Following the destination criteria, establishing a system to monitor all living organisms on the destination with the details and list of heritage assets and biodiversity is required to prevent future risk [10]. It is due to the role of the human as a consumer of natural heritage to be responsible for the environmental protection and conservation through the commitment of policy, regulations, and monitoring system ${ }^{[19]}$. In Accordance to the Secretariat of the Convention on Biological Diversity, the relationship between tourism and biodiversity are likely to support each other, while tourism needs the nature and biodiversity to present to the visitor, the natural resources also need protection by the sectoral to keep as green and as protected as possible; thus, the environmental policies on the natural resources need to equally recognize the positive and negative impact of tourism on biodiversity along with the strategy and action plan on the planning and management; the range of the information biodiversity should include details of areas and significant biodiversity, ecosystem habitats and species, quality of habitats, wildlife populations, potentials threats and the level of stakeholder awareness regarding biodiversity value and impact on conservation ${ }^{[12]}$.

4.2 Principle D(b) Resources Management; this section also shows a 100\% of non-compliance (NC), as described in the chart and table below;

Figure 9 Principle D(b)
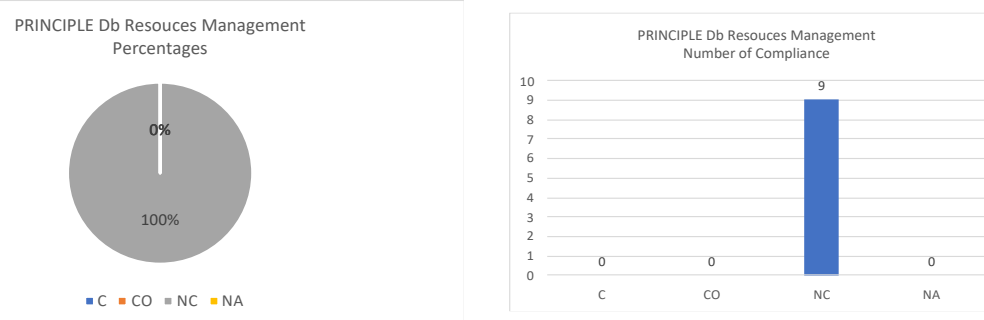

The non-compliance appeared due to the absence of data concerning resource management on energy, water, and target consumption; lack of data towards planning, strategy, and key stakeholder statement to support resource management consumption also appears as an NC.

Following the criteria, destinations should be documented a data for energy consumption, energy sufficiency, and renewable energy to create a responsible use of energy ${ }^{[10]}$, due to the dependence of tourism on energy resources would release the carbon emission[42]. Thus, the sufficiency of sustainable consumption on a multidimensional is necessary to balance the development ${ }^{[35]}$. Moreover, as a complex sector coverage many stakeholders, good planning, strategy, and implementation will help tourism to come out from the un-sustainable development by the campaign to use the renewable energy [42], reduce and replace with longevity product, and make a cooperate with all related parties to change the visitor behaviour, attitude, and culture ${ }^{[35]}$, and a commitment from the key stakeholder to help tourism enterprise to use the renewable energy easily by the policy to reduce the cost of renewable energy ${ }^{[48]}$. The destination also needs to establish guidance to ease the water usage by the tourism industry with a water risk program, monitor the water sources, and encourage visitor encouragement to reduce water use ${ }^{[10]}$. Due to the number of water consumption by tourism shows a high percentages ${ }^{[17]}$, that also lead by the unregulated water privatisation and low level of awareness regarding water resource; thus, all related parties need to take into account in regards to water management [9]. Moreover, there are several things that need to be considered; renewable water resources, water management for the industry, limited international product which creates more footprint, limited energy use per guest, low-flow option for the shower, dual flush option and low flow tap, and limited laundry per guest per night [17]. Furthermore, water quality assessment also needs to be obtained to ensure the water for tourist safety and hygiene ${ }^{[10]}$.

4.3 Principle D(c) Management of Waste and Emissions; this section also shows $100 \%$ of noncompliance in accordance with the data from RIPPARKAB report Year 2014, as described in a chart and table below; 
Figure 10 Principle D(c)
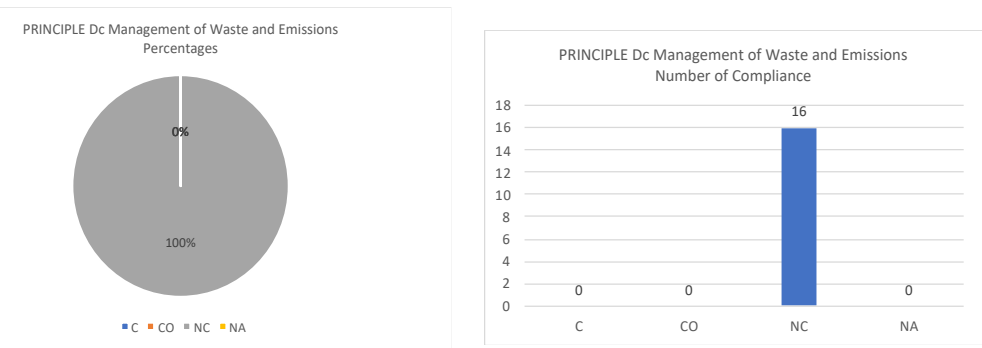

In accordance with the analysis result, some issues appeared on the strategy development (RIPPARKAB), including the absence of the guidelines and assessment on waste management, including wastewater and solid waste; the lack of data from tourism enterprise regarding the reuse, reduce, and recycle solid waste on their operation; the commitment from the government to eliminate the single-use plastic with the details on disposed of the solid waste; the green-house-gases and climate change mitigation and adaptation both the stakeholders data and the commitment from the government to support the enterprise; low-impact and low-emission transportation along with the guidelines for the tourism stakeholders towards light and noise pollutions. According to the interviews with the local community and local enterprise, lack of communication from the destination to the local enterprise and community towards resources management (energy, waste, and water), plastics issues, encouragement to reduce and minimize the mitigation create a gap and become a significant problem on the development. Local community and enterprise mentioned "there is no monitoring from the government pertaining to waste management, its only local community the one who responsible for the waste management. It is barely hard to communicate to the destination to discuss these issues". According to the field observation, bin of waste separation has been in place; however, a lack of implementation and maintenance regarding the trash bin raised an issue on the ground.

Following the criteria, the systematic guidelines, policy, system, monitoring, treatment, and enforcement concerning waste management (both wastewater and solid waste) need to be written to ensure the safety of the litter when released to the environment ${ }^{[10]}$. For example, Indonesia DMC Sustainability Collaboration (IDSC) promoted and encouraged the tourism enterprise in Bali regarding wastewater treatment and solid waste recycling [2], which could decrease the water bills and help to reduce the non-recyclable waste [27]. The number of waste generated by the tourism activity is also getting higher, especially the municipal waste gradually destroying the environment ${ }^{[30]}$. Hence, waste management, waste separation, banning single plastic, and promoting reusable items must be implemented to related parties [2], food waste prevention and campaign, waste measurement, and provide the alternative of reusable on every activity [30]. Moreover, reducing greenhouse emissions and environmentally friendly transportation should concern tourism development to protect the environment from the development ${ }^{[10]}$. Several things need to consider to create sustainable tourism, including green economy, waste management, resource management, green regulations, green activity, green destination, and green transportation, which will help to increase people awareness on sustainability issues, protect the environment, and increase the prosperity in the local development ${ }^{[48]}$. Finally, light and noise pollutions data, guidelines, system, identification, monitoring, and mechanism must be in place ${ }^{[10]}$.

\section{CONCLUSIONS}

As s conclusion, the result of Tanjung Kelayang sustainable destination performance by GSTC-D V2, as described below:

A

\begin{tabular}{c|c}
$\begin{array}{c}\text { GSTC } \\
\text { Performance }\end{array}$ & $\begin{array}{c}\text { Sustainable } \\
\text { Management }\end{array}$ \\
\hline C & 7 \\
CO & 4 \\
NC & 23 \\
NA & 0 \\
Total & 34
\end{tabular}

Table 3 Summary of the Result

$$
\text { B C D }
$$

Socio-

Economic Sustainability
TOTAL Sustainability 
As a summary, Section A. Sustainable Management average percentages for the compliance was $19 \%, 12 \%$ for compliance with observation, $0 \%$ of the non-application indicator, and $68 \%$ for non-compliance out of 34 totals of indicators. It shows the non-conformity dominates the percentages of section A. Lack of human resources and awareness on sustainable tourism development become the main problems in Tanjung Kelayang tourism development, creating a huge gap between non-compliance and compliance. A concept on maintaining, evaluating, and review process still yet shown effectiveness on their development as informed in the report of RIPPARKAB that only has one version in 2014. Lack of communication and engagement with related parties, especially with the local community, creates a gap in sustainability knowledge. Thus, tourist and local community satisfaction measurements must be in place to prevent misunderstandings concerning tourism development. Furthermore, identifying climate change risk, adaptation, and the emergency response plan must be in place to mitigate the risk and crisis, and increase the health and safety destination, increasing the trust from tourists to Tanjung Kelayang.

Section B. Socio-Economic Sustainability average percentages for the compliance is $4 \%, 8 \%$ for compliance with the observation, $0 \%$ for the non-applicable, and $88 \%$ for the non-compliance out of 19 indicators. To sums up, the non-compliance label dominates the percentages in section B. Deep analysis, identification, report, and evaluation system pertaining to the exploitation and discrimination, indirect tourism sectoral, sustainability engagement, crime, safety, and hazard is yet written on the RIPPARKAB. Accordingly, it has become a crucial challenge on the development. Lack of awareness in liability insurance also became a huge problem that could increase a future risk on development. Furthermore, as a guidance, the RIPPARKAB should obtain all data details to shows the guidelines that need to be occurred by the industry. A monitoring and evaluation system were also necessary to ease the tracking system for the certification body, public, local community, and the private sector. Thus, it shows all related parties support the commitment to tourism development based on socio-economic and human rights against exploitations and discriminations.

Section C. Cultural Sustainability average percentages for the compliance is $11 \%, 0 \%$ for the compliance with observation, $6 \%$ for the non-applicable, and $83 \%$ for the non-compliance. Up until section C, the non-compliance label still dominant the data. The indicator in this section is 16 in total. Evaluation and monitoring systems still become prominent issues. Moreover, laws towards historical sales are necessary to protect the culture.

Furthermore, lack of data on the details of biodiversity condition in the destination and the strategy to protect and preserve is essential to plan and measure the conservation and rehabilitation. Visitor management regarding cultural impact is also necessary to measure the adverse effects that might appear in the future. Details information destination should be written to show the government's commitment to protecting the destination's culture. The data also need to cover the sensitivity and the interpretation to respect the destination, and local residence believes

Section D. Environmental sustainability shows $100 \%$ of non-compliance with 38 indicators in total. The absence of data towards natural heritage conservation, resources management, waste management, and emissions control and management has become a significant gap in Tanjung Kelayang tourism development plan and strategy. Accordingly, deep analysis concerning the environmental and natural issues with biodiversity and all living organism is necessary to be in place to fill the gap between GSTC-D V2 with the RIPPARKAB document 2014, which will led to sustainable destination.

Hence, environmental sustainability becomes the most fragile principle that should be considered. Data organizing and deep analysis regarding each indicator need to be obtained to understand the concept of a sustainable destination. In such a way, the lack of local community and enterprise involvement and development creates a gap in implementation. At the same time, a comprehensive analysis of the socio-economic development should be in place along with the documentation and commitment with the mature planning and well manage implementation. Moreover, cultural sustainability must be recognized to empower local community livelihood and to conserve the heritage. Sustainability management principle with the periodic monitoring and evaluation system is necessary to create a balanced development.

\section{REFERENCES}

[1] Ajayi VO. Primary Sources of Data and Secondary Sources of Data. Benue State University 2017.

[2] Andrariladchi H. RAISING THE AW ARENES OF SUSTAINABILITY AND HEALTH \& SAFETY FOR TOURISM. 2019. Bali: Indonesian DMC Sustainability Collaboration (IDSC).

[3] Antara M and Sumarniasih MS. Role of tourism in economy of Bali and Indonesia. Journal of Tourism and Hospitality Management 2017; 5: 34-44.

[4] Bagul P and Bahar AH. Success of ecotourism sites and local community participation in Sabah. 2009.

[5] Bahja F and Hancer M. Eco-guilt in tourism: Do tourists intend to behave environmentally friendly and still revisit? Journal of Destination Marketing \& Management 2021; 20: 100602. 
[6] Baumgartner C, Beyer M, Iwaszuk E, et al. Human Rights in Tourism. Analysis of the Challenge Recommendations to Public and Private Stakeholders Report to the GIZ(Unveröffentlichter Entwurf) 2015.

[7] Buckley R. Sustainability reporting and certification in tourism. Tourism Recreation Research 2012; 37: 85-90.

[8] Cleverdon R and Kalisch A. Fair trade in tourism. International Journal of Tourism Research 2000; 2: 171-187.

[9] Concern T. Water Equity in Tourism-A Human Right, A Global Responsibility. Posyskano z bttp://wmw tourismconcern org uk 2016.

[10] Council GST. GSTC Destination Criteria Version 2.0 with Performance Indicators and SDGs, https://www.gstcouncil.org/wp-content/uploads/GSTC-Destination-Criteria-v2.0.pdf (2019).

[11] Deny S. 10 Bali Baru Bakal Jadi Kawasan Ekonomi Khusus. liputan6, 2018.

[12] Diversity SotCoB. Tourism Supporting Biodiversity: A Manual on Applying the CBD Guidelines on Biodiversity and Tourism Development. In: 2015, Secretariat of the Convention on Biological Diversity.

[13] Dwyer L, Edwards D, Mistilis N, et al. Destination and enterprise management for a tourism future. Tourism management 2009; 30: 63-74.

[14] Farhan A. Cerita Menteri Pariwisata Memilih 10 Bali Baru. detik,com, 24 April 2019, 14:25 WIB 2019.

[15] George BP and Varghese V. Human rights in tourism: Conceptualization and stakeholder perspectives. EJBOElectronic Journal of Business Ethics and Organization Studies 2007.

[16] Giriwati NSS, Hawa LC, Pamungkas ST, et al. Local community participation in ecotourism development: the case of Sumberwangi Hamlet Destination, East Java, Indonesia. PEOPLE: International Journal of Social Sciences 2019; 5: 81 .

[17] Gössling S. New performance indicators for water management in tourism. Tourism Management 2015; 46: 233 244.

[18] GSTC. About GSTC, https://www.gstcouncil.org/about/about-us/ (2020, accessed 28-09-2020 2020).

[19] Hosseini K, Stefaniec A and Hosseini SP. World Heritage Sites in developing countries: Assessing impacts and handling complexities toward sustainable tourism. Journal of Destination Marketing \& Management 2021; 20: 100616.

[20] Hox JJ and Boeije HR. Data collection, primary versus secondary. 2005.

[21] Islands II. The "10 New Bali's" Explained The Future of Tourism in Indonesia, https://investislands.com/ten-new-bali-project/ (2019).

[22] Kabir SMS. Basic guidelines for research: An introductory approach for all disciplines. Book Zone Publication, Chittagong 2016.

[23] Kebete Y and Wondirad A. Visitor management and sustainable destination management nexus in Zegie Peninsula, Northern Ethiopia. Journal of Destination Marketing \& Management 2019; 13: 83-98.

[24] Kumar A. Cultural and heritage tourism: A tool for sustainable development. Global Journal of Commerce \& Management Perspective 2017; 6: p56-59.

[25] Loehr J and Becken S. The Tourism Climate Change Knowledge System. Annals of Tourism Research 2021; 86: 103073

[26] Manente M, Minghetti V and Celotto E. Visitor and mobility management in tourism destinations: A cross analysis of strategies, projects and practices. The Tourist Review 2000.

[27] MARTINA RYSULOVA DK, GABRIEL MARKOVIC, FRANTISEK VRANAY. Water saving plan by water reuse in the hotel building. WSEAS Transactions on Environment and Development 2015; 11: 41-48.

[28] Murzyn-Kupisz M. Cultural, economic and social sustainability of heritage tourism: issues and challenges. Economic and Environmental Studies (E⿺辶ES) 2012; 12: 113-133.

[29] Mushi YB. An assessment of sustainable tourism in Tanzania. Proposal of Master, UNITED STATES INTERNATIONAL UNIVERSITY, UNITED STATES INTERNATIONAL UNIVERSITY, Fall 2013.

[30] Obersteiner G, Gollnow S and Eriksson M. Carbon footprint reduction potential of waste management strategies in tourism. Environmental Development 2021: 100617.

[31] Okech R, Haghiri M and George BP. Rural tourism as a sustainable development alternative: An analysis with special reference to Luanda, Kenya. CULTUR-Revista de Cultura e Turismo 2015; 6: 36-54.

[32] Pathak A, van Beynen PE, Akiwumi FA, et al. Impacts of climate change on the tourism sector of a Small Island Developing State: A case study for the Bahamas. Environmental Development 2021; 37: 100556.

[33] Patton MQ. Qualitative research \& evaluation methods: Integrating theory and practice. Sage publications, 2014.

[34] Roxas FMY, Rivera JPR and Gutierrez ELM. Mapping stakeholders' roles in governing sustainable tourism destinations. Journal of Hospitality and Tourism Management 2020; 45: 387-398.

[35] Sandberg M. Sufficiency transitions: A review of consumption changes for environmental sustainability. Journal of Cleaner Production 2021: 126097. 
[36] Sayeda T. The effects of mass tourism: An evaluative study on Cox's Bazar, Bangladesh. IOSR Journal Of Humanities And Social Science (IOSR-JHSS) 2017; 22: 31-36.

[37] Scott D, Hall CM and Gössling S. Global tourism vulnerability to climate change. Annals of Tourism Research 2019; 77: 49-61.

[38] Shafieisabet $\mathrm{N}$ and Haratifard S. The empowerment of local tourism stakeholders and their perceived environmental effects for participation in sustainable development of tourism. Journal of Hospitality and Tourism Management 2020; 45: 486-498.

[39] Shopova I and Arabska E. Sustainable tourism development in rural areas. In: 4th International Conference of Economic Sciences 2013, pp.535-546.

[40] Smith J. Tak Banyak Pihak Sadar, Bali Terancam Kehabisan Air Tanah Akibat Industri Pariwisata. VICE, 2018.

[41] Sutawa GK. Issues on Bali tourism development and community empowerment to support sustainable tourism development. Procedia economics and finance 2012; 4: 413-422.

[42] Tian X-L, Bélaïd F and Ahmad N. Exploring the nexus between tourism development and environmental quality: Role of Renewable energy consumption and Income. Structural Change and Economic Dynamics 2021; 56: 53-63.

[43] UNWTO E. Sustainable tourism for development guidebook. World Tourism Organization, European Commission, Madrid 2013.

[44] Ural M. Risk management for sustainable tourism. European Journal of Tourism, Hospitality and Recreation 2016; 7: 63-71.

[45] Ward-Perkins D and Dimanche F. Controlling and Influencing Visitor Flow as a Basis for Sustainable Tourism Management. 2012.

[46] Warren C and Wardana A. Sustaining the unsustainable? Environmental impact assessment and overdevelopment in Bali. Asia Pacific Journal of Environmental Law 2018; 21: 101-125.

[47] World Travel \& Tourism Council: Environmental S, \& Governance Reporting in Travel \& Tourism. SUSTAINABILITY REPORTING IN TRAVEL \& TOURISM. September 2017 2017. United Kingdom: WTTC.

[48] Zhang S and Liu X. The roles of international tourism and renewable energy in environment: new evidence from Asian countries. Renewable energy 2019; 139: 385-394. 